\title{
Atividade física orientada para as crianças brasileiras
}

Ao final dos Jogos Olímpicos de Sydney, muito se disse e se escreveu sobre o desempenho do Brasil. Falou-se de fatores psicológicos; falou-se da falta de infra-estrutura para o esporte de alto rendimento no Brasil; falou-se da falta de intercâmbio com atletas de outros países; falou-se de ingerências políticas na condução do esporte brasileiro. Não é o objetivo deste Editorial analisar o desempenho dos atletas brasileiros das diferentes modalidades; e nem discutir os pontos acima, os quais já foram - e continuam sendo - extensamente discutidos em diversos foros. $\mathrm{O}$ desempenho de uma equipe nacional em uma competição como os Jogos Olímpicos depende obviamente de uma multiplicidade de fatores. Gostaríamos de enfatizar um fator sobre o qual pouco se tem dito.

Muito se fala na massificação do esporte no Brasil. Gostaríamos de ir mais além. Gostaríamos de discutir a facilitação do acesso à prática orientada de atividade física para crianças em idade escolar.

Hoje no Brasil uma minoria de crianças tem acesso a uma prática orientada de atividade física. São geralmente crianças de classes média e alta que têm acesso a clubes e academias. Ou algumas poucas que têm a sorte de desfrutar do resultado de iniciativas isoladas. Há um funil bastante fechado para obter um atleta de nível internacional. Até mesmo por uma questão matemática, se apenas uma minoria tem acesso à prática de atividade física, um percentual ainda menor praticará alguma modalidade desportiva de caráter competitivo e raros serão aqueles que atingirão um nível que os permita aspirar a uma medalha olímpica. Por outro lado, ao realmente democratizar o acesso à prática orientada de atividade física, existe a possibilidade de retirar talentos desportivos da clandestinidade à qual de outra forma estariam condenados.

E essa "democratização" teria impactos que iriam muito além do plano desportivo. Sob uma perspectiva de saúde pública, a médio e a longo prazos esse tipo de iniciativa teria um forte impacto na redução da incidência de uma série de doenças crônico-degenerativas, desonerando o sistema público de saúde. No último Congresso SulBrasileiro de Medicina do Esporte, realizado em Porto Alegre há pouco mais de um mês, tivemos a oportunidade de assistir a uma bela palestra do Dr. Oded Bar-Or, do Canadá. Um dos pontos mais interessantes foi o que ele denominou "epidemia de obesidade": um aumento importante e nítido da prevalência de obesidade a partir de uma determinada faixa etária. Esse fenômeno está associado principalmente com um índice mais baixo de atividade física. Autoridades de saúde dos Estados Unidos e do Canadá estão preocupadas com o aumento previsível da incidência de doenças crônico-degenerativas - particularmente cardiovasculares e metabólicas - que deve ocorrer daqui a algumas décadas, caso essa tendência não seja revertida. Estatísticas de saúde estimam que nos Estados Unidos mais de 250.000 indivíduos faleçam todos os anos, simplesmente por serem sedentários.

Assim, um maior acesso à prática orientada de atividade física terá um impacto também de saúde pública, visto que uma criança fisicamente ativa mais provavelmente será um adulto fisicamente ativo. Isso ajudará a reduzir a prevalência de sedentarismo no nosso país, atualmente em torno de 70\%. Essa questão não pode deixar de incluir a valorização da educação física escolar, com a sua sistematização desde a pré-escola até a universidade e o incentivo aos profissionais que aí atuam.

Entretanto, a coordenação dessas ações deve ser essencialmente governamental. Se o governo abdicar a essa responsabilidade, continuará havendo apenas esforços isolados e descoordenados como já ocorre hoje. Alguns comentaristas e autoridades que enxergam um pouco mais à frente já consideram os Jogos Olímpicos de Atenas em 2004 "perdidas" para nós. Dizem que temos que nos preocupar desde já com 2008. Podemos "esticar" um pouco esse exercício de futurologia. Se o governo federal encampar hoje essa questão como uma prioridade, implantando e mantendo programas de atividade física orientada para as crianças brasileiras em parceria com os governos estaduais e municipais, contando com a participação coadjuvante da iniciativa privada, provavelmente poderemos esperar de modo realista um maior número de medalhas nos Jogos Olímpicos de 2020 e uma menor incidência de doenças crônico-degenerativas já a partir de 2030.

\section{REFERÊNCIAS}

1. Lazzoli JK, Nóbrega ACL, Carvalho T, Oliveira MAB, Teixeira JAC, Leitão MB et al. Posicionamento Oficial da Sociedade Brasileira de Medicina do Esporte: Atividade física e saúde na infância e adolescência. Rev Bras Med Esporte 1998;4:107-9. 